\title{
SOSIALISASI DAN PEMBINAAN BUDIDAYA IKAN DALAM EMBER UNTUK KETAHANAN PANGAN
}

\author{
Juniarti, Nazwirman, dan Indra Kusuma \\ Fakultas Kedokteran, Universitas YARSI \\ Magister Manajemen, Universitas YARSI \\ Email: nazwirman@yarsi.ac.id
}

\begin{abstract}
The food crisis can be carried out only in Indonesia as a result of the Covid-19 pandemic. Concrete steps are carried out using empty yards around the housing. This activity provides sanitation fishers with knowledge and practices of fish cultivation in Banjar Wijaya Housing Tangerang City. On average they are married and their income is insufficient. The implementation method used is socializing in the form of counseling and assistance. Stages of activities carried out provide knowledge and arrange the necessary tools and manufacture of fish farming in buckets and vegetables. The selected fish is oxygen resistant. Maintenance for 42 days produces catfish and kale harvest. This activity should increase the participants' knowledge from the average of the correct answers.
\end{abstract}

\section{PENDAHULUAN}

Kebutuhan dasar bagi manusia yang harus dipenuhi setiap saat adalah masalah pangan. Pangan memiliki peran yang sangat penting bagi kehidupan suatu bangsa. Munculnya ketidakstabilan ekonomi akibat ketersediaan pangan lebih kecil dibandingkan kebutuhannya. Akibatnya berbagai gejolak sosial dan politik dapat juga terjadi jika ketahanan pangan menjadi terganggu. Sebagai dampak pandemi Covid-19 saat ini, krisis pangan dapat saja mengancam Indonesia. Upaya yang dapat dilakukan berbagai pihak mulai melakukan penghematan dan menanam bahan pangan lokal.
Memang diperlukan proses yang cukup panjang untuk menciptakan kesadaran warga masyarakat untuk bisa mewujudkan kegiatan ini. Memanfaatkan masa berdiam di rumah dengan berkebun dan budidya ikan seperti bayam merah, kacang panjang, sawi dan kangkung dll.

Salah satu langkah konkret yang dapat dilakukan diantaranya dengan memanfaatkan pekarangan kosong di sekitar perumahan. Kegiatan menanam sendiri sayuran dan budidaya ikan untuk konsumsi keluarga juga memberi rasa aman, karena sumbernya jelas. Sekarang cukup berisiko mendapatkan sayuran karena adanya pembatasan, jarang penjual sayuran yang biasa 
datang, mau ke pasar juga mungkin jauh. Upaya menanam selain mudah dibudidaya juga memiliki masa panen yang singkat, yaitu hanya tiga minggu seperti kangkung dan bayam. Saatnya gaya hidup hijau yaitu perilaku yang ramah lingkungan dibudayakan dan dijadikan tren baru dalam menghadapi era new normal, baik selama pandemi maupun setelah pandemi Covid-19 ini.

Meskipun jumlah produksi pangan saat ini tidak mengalami banyak perubahan dan masih dapat dikatakan aman, permasalahan krisis pangan tetap dapat terjadi kedepannya. Permasalahan yang paling besar terjadi pada distribusi pangan. Adanya pembatasanpembatasan, distribusi pangan menjadi lemah. Oleh sebab itu masyarakat dapat mulai dari memanfaatkan lahan kosong menjadi lahan produktif serta ramah lingkungan.

\section{KHALAYAK SASARAN}

Dari hasil observasi dilakukan di komplek Perumahan Banjar Wijaya Kota Tangerang pada umumnya memiliki fasilitas yang yang dapat digunakan untuk lebih produktif. Tiap cluster perumahan memiliki minimal 4 (empat) orang tenaga kebersihan. Ratarata mereka mendapatkan penghasilan cukup rendah dan jam kerja lebih kurang 5 jam perhari. Pendidikan merekapun relatif rendah. Selain itu seluruh petugas kebersihan yang ada sudah berkeluarga dan memiliki 2 (dua) anak bahkan ada yang sudah memiliki cucu. Tentunya secara ekonomi pendapatan sebanyak itu kurang mencukupi.

Signifikannya manfaat ketahanan pangan dan rendahnya pemanfaatan lahan di tengah masyarakat mendorong dilaksanakannya Pengabdian pada Masyarakat tentang sosialisasi penanaman serta pembudidayaan ikan pada tenaga kebersihan wilayah tersebut serta bisa mendapat pengetahuan mereka (Juniarti \& Nazwirman, 2019) dan meningkatkan nilai ekonomis (Nazwirman et al., 2020; Rostini et al., 2019; Rostini et al., 2017) serta penghasilan tambahan dengan memanfaatkan waktu luang mereka yang lebih bermanfaat dan menghasilkan.

Pemanfaatan lahan terbatas terus diupayakan untuk memenuhi kebutuhan pangan keluarga. Model ini mengintegrasikan budidaya ikan dan sayuran sekaligus pada lahan yang terbatas. Teknologi vertiminaponik 
lebih menguntungkan dibandingkan dengan teknik budidaya konvensional (Rokhmah et al., 2014). Budidaya ikan sistem akuaponik pada prinsipnya menghemat penggunaan lahan dan meningkatkan efisiensi pemanfaatan hara dari sisa pakan dan metabolisme ikan. Sistem ini merupakan budidaya ikan yang ramah lingkungan (Setijaningsih \& Chirulwan, 2015).

\section{METODE PELAKSANAAN}

Metode pelaksanaan yang digunakan oleh kelompok pengabdian masyarakat adalah mensosialisasikan dengan metode penyuluhan dan pendampingan tentang budidaya ikan dalam ember.

Tahapan kegiatan yang dilakukan meliputi: pembuatan budidaya ikan dan sayur dengan merangkai alat-alat yang diperlukan mencakup ember, arang kayu, gelas plastik, kawat, serta ikan lele, mengintrepretasikan dan merekomendasikan. Proses desain dan pembuatan sistem budidaya ikan lele dilaksanakan di perumahan Banjar Wijaya Kota Tangerang.

\section{HASIL DAN PEMBAHASAN}

Pembuatan budidaya ikan dan sayur dalam ember sebenarnya cukup hemat air karena cukup menggunakan ember berisi 78 liter dengan permukaan air setinggi $50 \mathrm{~cm}$ ( lebih kurang 60 liter air). Pada permukaan atas ember digantungkan gelas plastik yang berisi arang kayu sebagai media tanam kangkung. Supaya kangkung dapat tumbuh gelas plastik diberi lubanglubang kecil sebagai tempat masuknya air ke media.

Dalam satu buah media budidaya ikan dalam ember (budikdamber) luas lahan yang dibutuhkan lebih kurang $0,2 \mathrm{~m}^{2}$ yang mampu menampung sebanyak $60-100$ ekor ikan lele. Budikdamber ini juga menjadi media tanam kangkung. Tempat budidaya ikan yang digunakan cukup representative, mudah didapatkan, hemat dalam penggunaan air serta tambahan penanaman sayuran kangkung untuk memenuhi kebutuhan nabati.

Karakteristik budikdamber dapat dilihat selama empat puluh hari. Hal ini dilakukan untuk melihat bagaimana sistem sudah berjalan dengan baik sebagai media untuk tempat hidup ikan dan tanaman sayur (kangkung), serta 
untuk mengetahui tindakan perbaikan apa selanjutnya yang perlu dilakukan. Uji budikdamber dilakukan yaitu: (1) Daya tampung ikan yang dapat di pelihara dalam media ember dengan ukuran 7 sampai $12 \mathrm{~cm}$ adalah 70 ekor, karena daya tampung ember masih cukup mendukung kehidupan ikan. (2) Membuat lubang dipinggir ember untuk menjaga stabilitas tinggi air agar tidak tumpah keluar ketika hujan. (3) Tanaman sayuran yang di tanam di media budikdamber adalah kangkung aquaponik. Namun dapat juga menggunakan sayuran lain yang dapat di tanam secara aquaponik di media budikdamber seperti bayam.

Pertumbuhan kangkung yang cukup baik dengan jarak waktu panen yaitu 10-16 hari (selama 40 hari dapat dilakukan pemanenan kangkung sebanyak 3 kali).

Perlu diperhatikan suhu pada media budikdamber dipengaruhi suhu lingkungan baik hujan maupun panas dari matahari. Suhu air media budikdamber yang sesuai dengan kebutuhan hidup jenis ikan lele sangkuriang yakni $25-31,5^{\circ} \mathrm{C}$ (Elpawati et al., 2015; Yunus et a 2014). Kenaikan suhu dapat menimbulkan berkurangnya kandungan oksigen sehingga asupan oksigen berkurang dan dapat menimbulkan stres pada ikan. Suhu yang sesuai dapat meningkatkan aktivitas makan ikan sehingga ikan menjadi lebih cepat tumbuh.

Ikan lele hidup dalam derajat keasaman $(\mathrm{pH})$ antara 6.5-8 (Ristiawan et al., 2008). Selanjutnya $\mathrm{pH}$ dapat menyebabkan ikan menjadi stress, mudah terserang penyakit, produktivitasnya rendah. Perubahan $\mathrm{pH}$ ditentukan oleh aktivitas fotosintesis dan respirasi dalam ekosistem. Fotosintesis memerlukan karbondioksida $\left(\mathrm{CO}_{2}\right)$ yang oleh komponen autotroph dirubah menjadi monosakarida. Kadar ammonia dalam media budikdamber diduga naik bila ikan diberi pakan yang berlebihan. Hal tersebut didukung oleh fakta bahwa jika pakan berlebihan ikan lele menggantung di permukaan media. Batas optimum kandungan ammonia NH3 untuk pertumbuhan ikan lele yaitu $0.1 \mathrm{mg} / \mathrm{L}$ (Kordi \& Ghufron, 2010).

Kebutuhan terhadap kualitas air yang baik dalam pemeliharaan ikan secara intensif, memerlukan suatu teknologi yang berbasis ramah lingkungan agar rendahnya bahan organik di dalam media pemeliharaan dan rendahnya limbah yang terbuang ke 
perairan umum (Adharani et al, 2016; Supendi \& Muhammad, 2015). Sistem budidaya ikan dalam ember ini tidak memberikan limbah buangan ke perairan, hasil total suspended solid (TSS) yang disiphon dari media setiap 10 hari sekali justru dapat dimanfaatkan untuk pupuk tanaman.

Kelangsungan hidup (survival rate/SR) merupakan nilai perbandingan antara jumlah ikan yang hidup hingga akhir dengan jumlah ikan pada awal penebaran. SR yang didapatkan dari 40 hari pemeliharaan (Wijaya et al., 2014).

\section{Jenis Ikan budidaya}

Ikan yang sesuai dibudidaya dengan budikdamber adalah Ikan yang tahan oksigen rendah seperti ikan lele, patin, gabus, sepat dan betok, Tanaman yang dapat ditanam juga sangat tergantung dari jenis media yang digunakan. Jika menggunakan media arang, jenis tanaman yang bisa dibudidayakan di antaranya adalah kangkung dan bayam. Apabila menggunakan media media AKT (arang, kain, tanah) semua jenis tanaman bisa dibudidayakan (Nawa et al., 2015).

Apabila budidaya lele sekaligus menanam kangkung dalam ember, bahan-bahan yang dibutuhkan yaitu:
Ember ukuran 80 liter, Arang batok kelapa (dapat juga menggunakan arang lain dari tumbuhan), gelas plastic, benih lele ukuran 5-12 cm sejumlah 60-100 ekor, Tang, Kawat, Solder dan Bibit kangkung (Gambar 1).

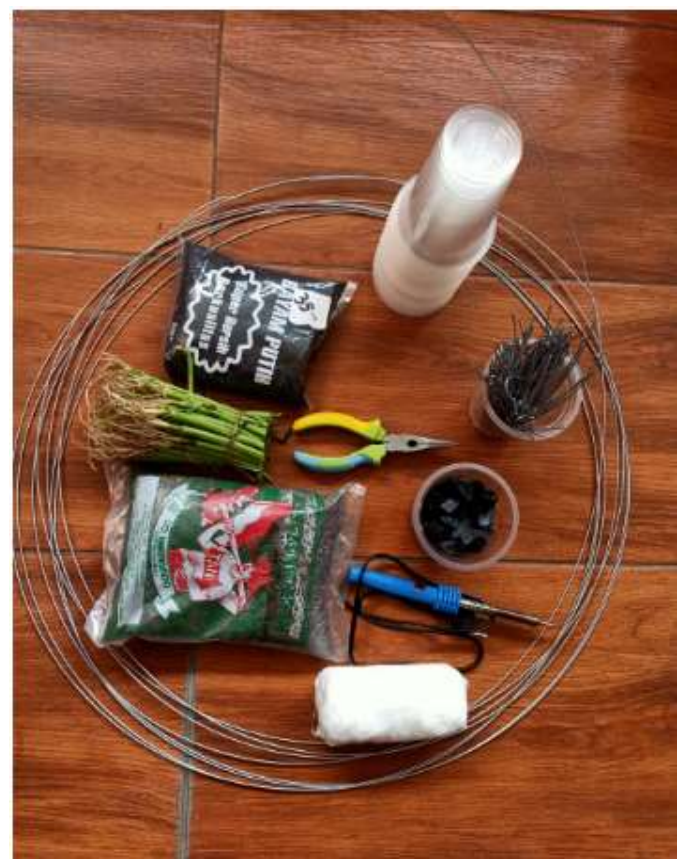

Gambar 1. Peralatan yang diperlukan

\section{Cara pembuatan budidamber dan tanam kangkung.}

Proses yang dilakukan Pertama yang dibutuhkan adalah mempersiapkan gelas dan potongan kangkung, caranya: Lubangi gelas plastik 10-15 buah dengan solder Potong kangkung sisakan bagian bawah Masukkan kangkung ke dalam gelas, kemudian isi gelas dengan arang antara 50 sampai 80 persen ukuran gelas. Potong kawat kurang lebih $12 \mathrm{~cm}$ dan buat model kait yang 
bisa dijadikan pegangan gelas di ember.

Selanjutnya adalah membuat persiapan media untuk Budikdamber Isi air 60 liter, diamkan kurang lebih 1-2 hari Masukkan ikan, diamkan 1-2 hari (Gambar 2).
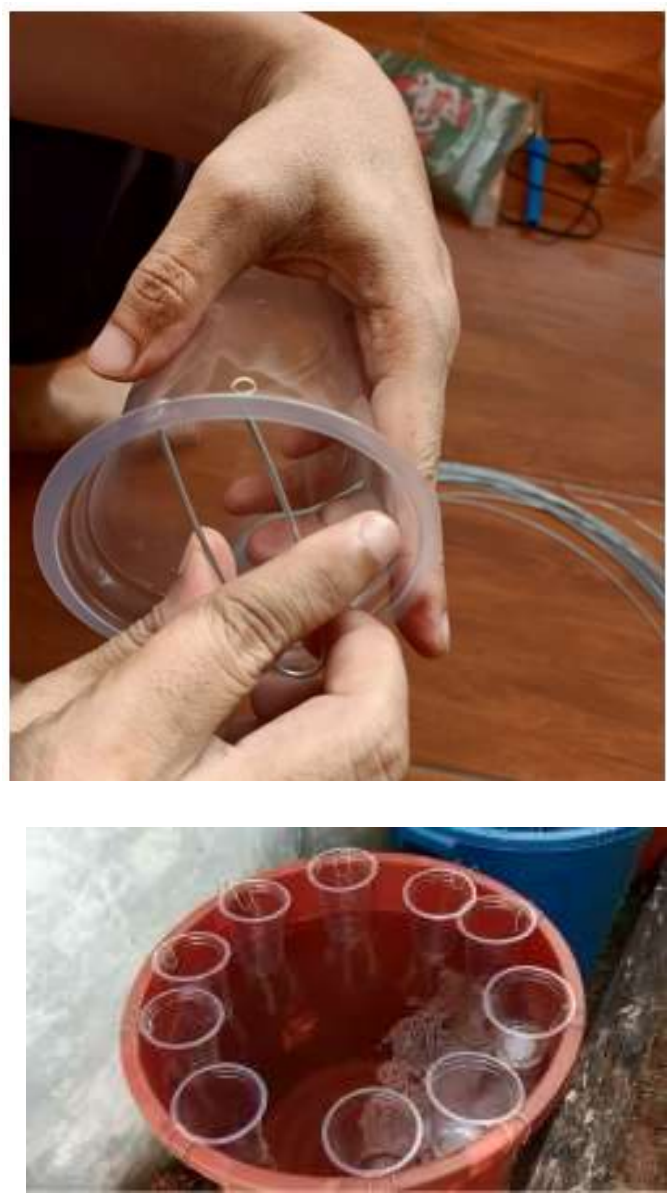

Gambar 2. Pembuatan

budidamber

Pemeliharaan

Untuk merawat lele dan kangkung yang dibudidayakan bersama, maka ember perlu diletakkan di tempat yang terkena matahari maksimal. Sehingga nantinya, kangkung terlihat tumbuh pada hari ke-3. Namun perlu diperhatikan, apabila terdapat kutu di daun kangkung maka segera buang daun atau batang karena kangkung keriting dan mati. Sedangkan untuk pakan ikan lele, bisa diberikan 2-3 kali dengan waktu yang rutin. Untuk ukuran ikan sepanjang 5-7 cm, maka pakan menggunakan pf800, ikan sepanjang 10 cm dengan pakan pf100, dan lebih dari $12 \mathrm{~cm}$ diberikan pakan ikan lele 781-2, 781-1, 781. Selanjutnya nantinya air akan berubah menjadi hijau dan amati nafsu makan ikan. Lakukan penggantian air saat nafsu makan ikan menurun, air berbau busuk dan ikan menggantung (kepala di atas, ekor di bawah). Penggantian air atau sipon (penyedotan kotoran dasar ember dengan selang) biasanya sekitar 10-14 hari sekali. Penyedotan dilakukan 5-8 liter saja atau bila diperlukan, air diganti sepenuhnya.Perlu diketahui, kangkung yang membesar maka ia membutuhkan air yang lebih banyak.

\section{Panen}

Panen kangkung pertama dapat dilakukan 14-21 hari sejak tanam. Caranya adalah dengan memotong kangkung dan menyisakan bagian bawah tunas untuk pertumbuhan kembali. Panen umumnya bisa berjarak 10-14 hari sekali dan tanaman dapat 
bertahan kurang lebih 4 bulan. Untuk panen ikan lele dapat dilakukan dalam 2 bulan bila benih bagus dan pakan baik. Tingkat ketahanan hidup lele dengan cara ini berkisar 40-100 persen.

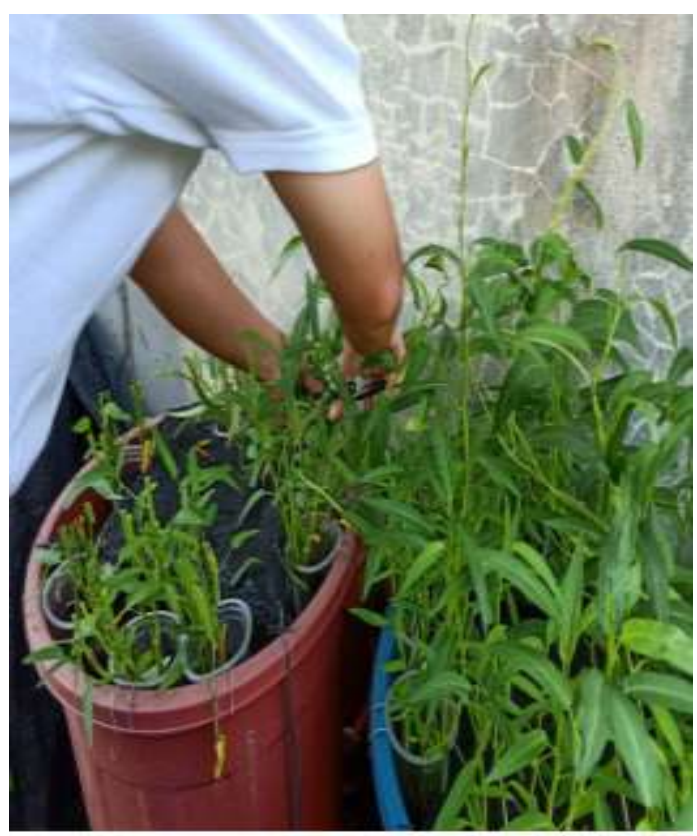

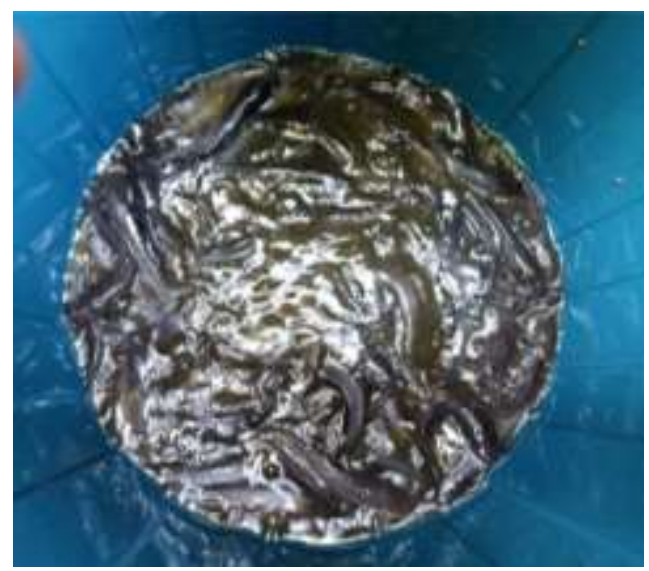

Gambar 3. Panen Kangkung dan penggantian air

\section{Pre dan post test}

Kegiatan ini juga melakukan evaluasi terhadap peserta tentang pemahaman yang mereka diterima. Adapun hasil yang diperoleh pre dan post test (Gambar 4) yaitu:

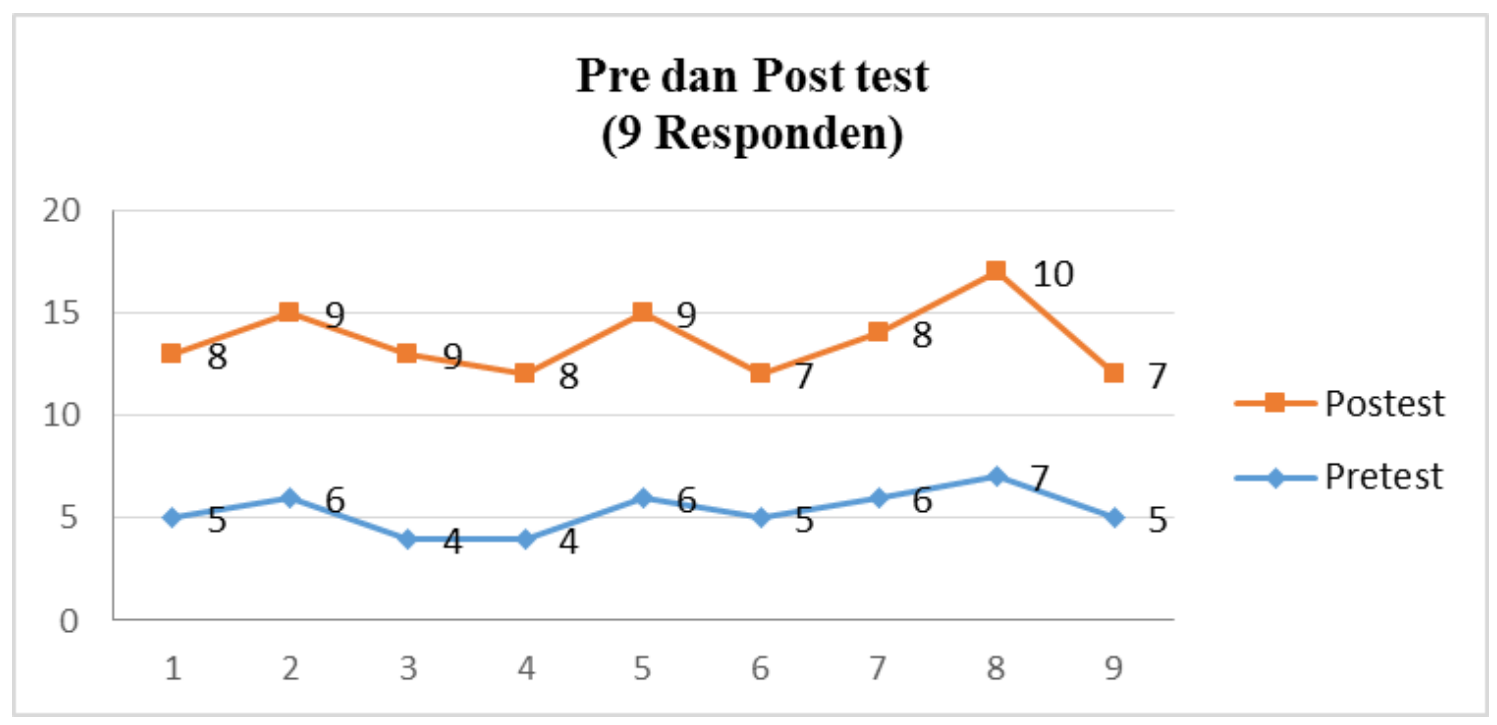

Gambar 4. Hasil pre dan postest peserta 
Dari 10 (sepuluh) indikator pertanyaan (Gambar 4) terkait pengetahuan manfaat tanaman surgawi yang diberikan sebanyak 9 orang peserta. Tampak pengetahuan yang diterima oleh peserta terjadi kenaikan dengan rata-rata hasil jawaban benar 5,33 (pre test) dan menjadi 8,33 (post test) jawaban. Hal tersebut menujukkan bahwa kegiatan ini cukup berhasil meningkatkan pengetahuan peserta. Proses sosialisasi yang dilakukan dengan penyuluhan dan praktik metode budidamber. Dalam kegiatan yang dilaksanakan kerjasama Universitas Yarsi dan petugas kebersihan Banjar Wijaya Kota Tangerang. Diantara para peserta kegiatan sosialisasi dan budidamber (Gambar 5).

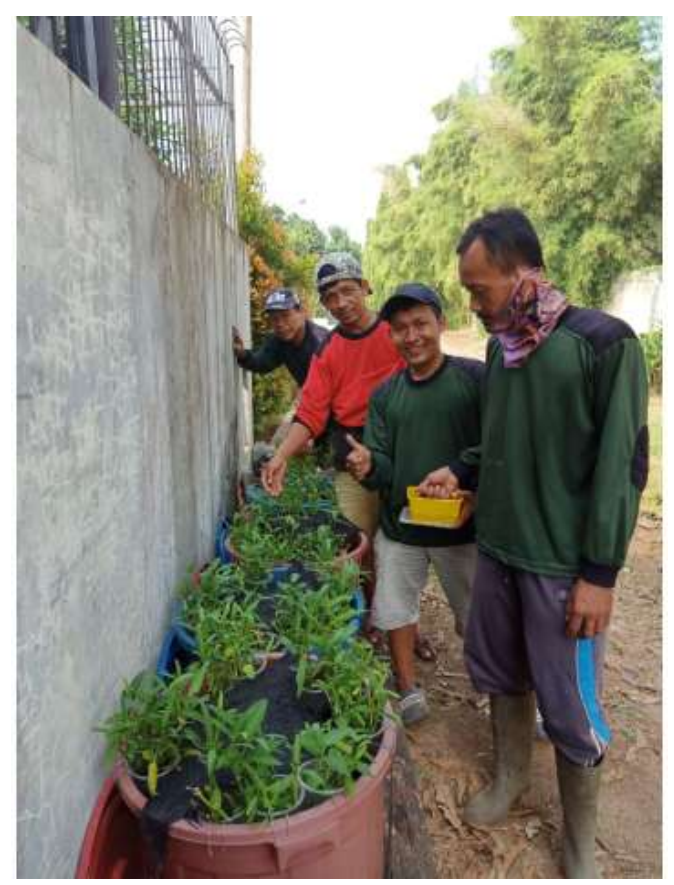

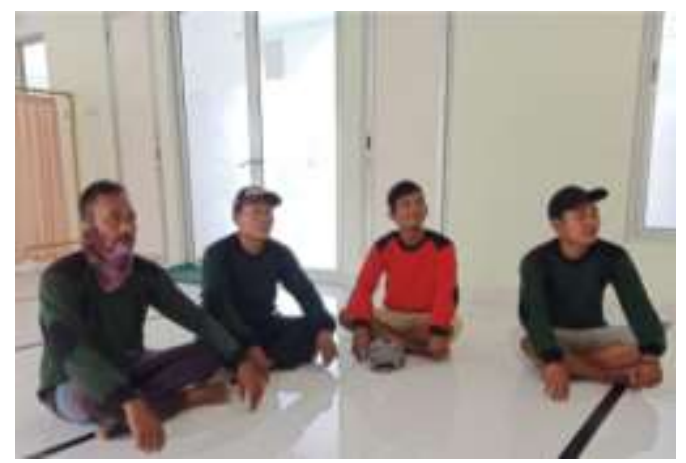

\section{Gambar 5. Kegiatan pelaksanaan}

Kegiatan sosialisasi manfaat dan budidaya tanaman surgawi pada petugas kebersihan di lingkungan Perumahan Banjar Wijaya Kota Tangerang dilakukan dengan penyuluhan tentang budidamber dan peragaan budidayanya. Dalam kegiatan yang dilaksanakan kerjasama Universitas Yarsi dan petugas kebersihan. Peserta yang hadir sebanyak 9 orang tidak termasuk panitia.

\section{KESIMPULAN}

Dampak pandemi Covid-19 saat ini, krisis pangan dapat saja mengancam Indonesia. Langkah konkret yang dapat dilakukan memanfaatkan pekarangan kosong di sekitar perumahan. Perumahan Banjar Wijaya Kota Tangerang memiliki fasilitas yang yang dapat digunakan untuk lebih produktif. Tiap cluster perumahan memiliki minimal 4 (empat) orang tenaga kebersihan. Rata-rata mereka sudah 
berkeluarga dan memiliki 2 (dua) dan pendapatan kurang mencukupi. Metode pelaksanaan yang digunakan pengabdian masyarakat adalah mensosialisasikan dengan penyuluhan dan pendampingan budidaya ikan dalam ember. Tahapan kegiatan yang dilakukan dengan pembuatan budidaya ikan dan sayur serta merangkai alat-alat yang diperlukan. Budidaya ikan dalam ember (budidamber) merupakan ikan yang tahan oksigen rendah yaitu lele sangkuriang dan bibit kangkung. Pemeliharaan selama 42 hari menghasilkan ikan lele yang lebih besar dan panen kangkung. Kegiatan ini meningkatkan pengetahuan peserta diketahui dari rata-rata hasil jawaban benar.

\section{UCAPAN TERIMA KASIH}

Penulis mengucapkan banyak terima kasih kepada Yayasan Universitas Yarsi dengan pendanaan yang diberikan. Seluruh anggata pengabdian serta peserta petugas kebersihan Banjar Wijaya kota Tangerang.

\section{DAFTAR PUSTAKA}

Adharani, Nadya, Kadarwan Soewardi, Agung Dhamar Syakti, Sigid Hariyadi. (2016). Manajemen
Kualitas Air Dengan

Teknologi Bioflok: Studi Kasus Pemeliharaan Ikan Lele (Clarias Sp.). Jurnal Ilmu Pertanian Indonesia (JIPI), 21 (1): 35-40

Elpawati, Dianna Rossyta Pratiwi, Nani Radiastuti. (2015). Aplikasi Effective Microorganism 10 (EM10) Untuk Pertumbuhan Ikan Lele Sangkuriang (Clarias gariepinus var. Sangkuriang) Di kolam Budidaya Lele Jombang. AlKauniyah Jurnal Biologi. 8(1).

Juniarti \& Nazwirman. (2019). Sosialisasi Kehalalan Kosmetik Dan Barang Guna. Jurnal Abdimas. 5(4): 229234

Kordi M. \& Ghufran H. (2010). Budidaya Ikan Lele Di Kolam Terpal. Yogyakarta: Lily Publisher.

Nawa, Satria Wicaksana, Sri Hastuti, Endang Arini. 2015. Performa Produksi Ikan Lele Dumbo (Clarias gariepinus) yang dipelihara dengan Sistem Biofilter Akuaponik dan Konvensional. Journal of Aquaculture Management and Technology. 4(4): 109116.

Nazwirman, Juniarti, dan Zainal Zawir Simon. (2020). Penyuluhan Dan Pembinaan Manfaat dan Budidaya Tanaman Surgawi. Jurnal Pengabdian Al-Ikhlas. $6 \quad$ (1), 54-65. DOI: http://dx.doi.org/10.316 02/jpaiuniska.v6i1.3366

Ristiawan Agung Nugroho, Lilik Teguh Pambudi, Diana Chilmawati \& Alfabetian Herjuno Condro 
Haditomo. (2012). Aplikasi teknologi Aquaponik pada Budidaya Ikan Air Tawar Untuk optimalisasi Kapasisras Produksi. Jurnal Saintek Perikanan. 8(1): 46

Rokhmah, Nofi A., Chery Soraya Ammatillah, \& Yudi Sastro. (2014). Mini Akuaponik untuk Lahan Sempit di Perkotaan. Buletin Pertanian Perkotaan. 4(2).

Rostini, Tintin, Muhammad Irwan Zakir, Danang Biyatmoko. (2019). Peningkatan Nilai Ekonomis Limbah Pertanian Di Pedesaan Melalui Tekhnologi Bokashi Dikelompok Tani Martapura, Kabupaten Banjar. Jurnal Pengabdian Al-Ikhlas. $\quad 4(2): 104-112$. DOI:

Http://Dx.Doi.Org/10.316 02/Jpaiuniska.V4i2.1947

Rostini, Tintin, Muhammad Irwan, Zakir, Rizqi Elmuna Hidayah. (2017). Peningkatan Produktivitas Kambing Di Kelompok Ternak Kambing Kecamatan Cempaka Kota Banjarbaru Kalimantan Selatan. Jurnal Pengabdian
AlIkhlas. 3(1): 22-29. DOI: http://dx.doi.org/10.31602/jpa i.v3 11.922

Setijaningsih, Lies dan Chairulwan Umar. (2015). Pengaruh Lama Retensi Air Terhadap Pertumbuhan Ikan Nila (Oreochromis Niloticus) Pada Budidaya Sistem Akuaponik dengan Tanaman Kangkung. Berita Biologi, Jurnal Ilmuilmu Hayati. 14(35).

Supendi \& Muhammad Rizki Maulana. (2015). Teknik Pembesaran Ikan Lele dengan sistem akuaponik. Bul. Tek. Lit. Akuakultur. 13(2): 101-106

Wijaya, Ongky, Boedi Setya Rahardja \& Prayogo. (2014). Pengaruh Padat Tebar Ikan Lele Terhadap Laju Pertumbuhan dan Survival Rate pada Sistem Akuaponik. Jurnal Ilmiah Perikanan dan Kelautan. 6 (1).

Yunus, Taufiq, Hasim \& Rully Tuiyo. (2014). Pengaruh Padat Penebaran Berbeda terhadap Pertumbuhan Benih Ikan Lele Sangkuriang di Balai Benih Ikan Kota Gorontalo. Nike Jurnal Ilmiah Perikanan dan Kelautan. 2(3). 